\title{
Comparative Study on Energy Utilization Efficiency of High-tech Enterprises in Beijing-Tianjin-Hebei and Yangtze River Delta
}

\author{
Gao Pengcheng ${ }^{1, *}$ \\ ${ }^{1}$ School of management of Tianjin University of Technology, research Centerior circular economy and sustainable development of \\ enterprises, Tianjin 300384
}

\begin{abstract}
Using panel data from the Beijing-Tianjin-Hebei and Yangtze River Delta regions from 2014 to 2018, combined with the DEA model and the Malmquist index method, the energy efficiency of high-tech enterprises and their decomposition items are compared from both static and dynamic aspects. The results show that the overall energy utilization efficiency of the two places is in a state of continuous improvement. From 2014 to 2016, the efficiency of high-tech enterprises in the Beijing-Tianjin-Hebei region was better than that of the Yangtze River Delta region, but it was overtaken by the Yangtze River Delta region from 2017 to 2018. In contrast, the advantage of the Beijing-Tianjin-Hebei region lies in pure technical efficiency, and the advantage of the Yangtze River Delta region lies in scale efficiency.
\end{abstract}

\section{Introduction}

In the era of knowledge economy, high-tech has become the key to a new round of economic transformation by virtue of higher social and economic benefits, and innovation is the inexhaustible source of power for high-tech. Since the implementation of the innovation-driven development strategy, my country's high-tech enterprises have gradually stepped out of the low-end of the international industrial chain under a technology innovation system with enterprises as the main body, market-oriented, and in-depth integration of production, education and research, and high-tech achievements have entered the world market. Today, the Beijing-Tianjin-Hebei and Yangtze River Delta city clusters are important sources of innovation in China, with abundant innovation resources, sufficient innovation motivation, and a high degree of openness. They play a decisive role in the overall innovation and development of the country. Comparing and analyzing the innovation efficiency of high-tech enterprises in the Beijing-Tianjin-Hebei and Yangtze River Delta regions, and learn from each other, has important theoretical and practical significance to promote the sustainable development of high-tech and high-tech achievements in the two regions.

\section{Literature review}

Current scholars' research on innovation efficiency mainly focuses on the exploration and improvement of measurement methods and the evaluation and application of regions, enterprises, and industries. Regarding the measurement of regional innovation efficiency: Wang Jun used the panel data of 30 provincial administrative regions from 2010 to 2015 to measure the innovation economic efficiency of each region, and pointed out that the innovation efficiency of the eastern region is positively correlated with the degree of opening up to the outside world and the degree of marketization. Financial depth is negatively correlated; the innovation efficiency of the central and western regions is negatively correlated with the level of infrastructure and higher education $^{[1]}$; Guo Shufen and Zhang Jun build a regional innovation efficiency evaluation index system based on the Douglas production function. After comparing and categorizing the redundancy of scientific and technological innovation investment, it is pointed out that the country still needs to reform science and technology management policies and guide the region to optimize resource allocation at the current stage. Provinces and cities need to formulate science and technology innovation policies with local characteristics based on local technological redundancy ${ }^{[2]}$. In the measurement of enterprise innovation efficiency: Chen Weihua and Li Peng use the super-efficiency CCR-DEA model to calculate 31 provinces, municipalities and autonomous regions, and use a multiple regression model to explore the effect of enterprise innovation influencing factors. The conclusion shows that: government policies and innovation awareness are the main factors affecting enterprise innovation ${ }^{[3]}$; Chi Renyong conducted a questionnaire survey on 230 enterprises and measured the technological innovation efficiency of large, medium, and small enterprises, and carried out an analysis of each factor. Regression test shows that the ranking of enterprise technological innovation efficiency according to ownership is: foreign-funded enterprises, private enterprises, joint-stock companies, collective enterprises and

\footnotetext{
Corresponding author: 1102520034@qq.com
} 
state-owned enterprises; enterprise technological innovation methods and coordination of internal functional departments have a significant impact on technological innovation efficiency ${ }^{[4]}$. In terms of industry innovation efficiency measurement: Xiao Wen and Lin Gaobang used the stochastic frontier analysis method to measure the technological innovation efficiency of 36 industrial industries, and found that China's overall technological innovation efficiency is between 0.5 and 0.6 , and is market-oriented. The efficiency of technological innovation is significantly lower than that of non-market-oriented technological innovation $^{[5]}$; Yang Min and Chen Zeming believe that enterprises in the same industry can be compared through the innovation efficiency value obtained by the DEA model, but if you want to compare the performance of enterprises in different industries For the efficiency of technological innovation, it is necessary to use the respective innovation difficulty coefficients of different industries as a frame of reference to revise the innovation efficiency of enterprises in order to compare the innovation efficiency of enterprises in heterogeneous industries ${ }^{[6]}$. It can be seen from this that in recent years, the research on innovation efficiency has mainly focused on a single region, the comprehensive efficiency evaluation of the industry, and the analysis of input redundancy, and little attention has been paid to the research on the differences between regions with comparable economic development. There is a lack of exploration in areas where the level of innovation between regions is found to be insufficient through comparison.

\section{Measurement of innovation efficiency of high-tech enterprises in the Beijing-Tianjin-Hebei and Yangtze River Delta}

\subsection{Method introduction}

Step 1: Suppose there are $\mathrm{n}$ decision-making units, and each decision-making unit has $\mathrm{m}$ inputs Variable, and $\mathrm{s}$ output variables, the input and output variables are expressed as :

$$
\begin{aligned}
& x_{j}=\left[\begin{array}{llll}
x_{1 j}, & x_{2 j}, & \ldots, & x_{m j}
\end{array}\right] T \\
& \mathrm{y}_{\mathrm{j}}=\left[\begin{array}{llll}
\mathrm{y}_{1 \mathrm{j}}, & \mathrm{y}_{2 \mathrm{j}}, \ldots, \mathrm{y}_{\mathrm{mj}}
\end{array}\right] \mathrm{T} \\
& \mathrm{j}=1,2, \ldots, n
\end{aligned}
$$

Step 2: In order to perform subsequent calculations, input variables and output variables System processing separately:

$$
h j=u^{T} Y_{j} / v^{T} X_{j}
$$

Step 3: Perform efficiency evaluation and analysis on the $\mathrm{j}_{0}$ decision-making unit:

$$
\min \theta
$$

$$
\sum_{j=1}^{n} x_{j} \lambda_{j}+s^{-}=\theta x_{0}
$$

$$
\begin{array}{ll}
\text { S.t } . & \sum_{j=1}^{n} y_{j} \lambda_{j}-s^{+}=y_{0} \\
& \lambda_{j} \geq 0, j=1,2, \ldots, n \\
& s^{+} \geq 0, s^{-} \geq 0
\end{array}
$$

The Malmquist index uses a distance function to describe the production technology efficiency of multiple input variables and multiple output variables. It reflects the relative efficiency of decision-making units in adjacent periods. At the same time, the index can be decomposed into:

$\mathrm{M}=$ Techch $\times$ Effch $=$ Techch $\times$ Pech $\times$ Sech

Among them, Techch is the technological progress index, which reflects the changes in the production frontier during the inspection period, and is used to measure the degree of technological improvement or the ability to recreate in the technological production process; Pech is the pure technical efficiency index, which reflects the assumption that the return to scale remains unchanged Time technical efficiency is usually used to measure the growth rate of production efficiency brought about by pure technological progress excluding all tangible production factors; Sech is the scale efficiency index, reflecting the degree to which the decision-making unit tends to the optimal production scale.

\subsection{Selection of indicators and data}

This paper draws on the results of all parties and selects the full-time equivalent of $R \& D$ personnel and the internal expenditure of $R \& D$ funds as input variables based on the availability of data. The output is mainly considered from the economic and technological achievements, and the product sales revenue and the number of valid invention patents are selected as the measurement indicators.

The data in this article comes from the "China Science and Technology Statistical Yearbook" and "China Torch Statistical Yearbook", and use the consumer price index as the base period of 2014 to equalize the three indicators of R\&D internal expenditure, product sales income, and high-tech enterprise tax reduction and exemption. It has been compiled and integrated into a panel data set of high-tech enterprises in the Beijing-Tianjin-Hebei and Yangtze River Delta regions from 2014 to 2018.

\section{Comparison of innovation efficiency of high-tech enterprises in Beijing-Tianjin-Hebei and Yangtze River Delta}

\subsection{Static efficiency analysis based on DEA model}

According to DEAP2.1 software, calculate the technological innovation performance evaluation index 
of high-tech enterprises in major provinces and cities in the Beijing-Tianjin-Hebei and Yangtze River Delta regions.

Table1 2014 2018 Beijing-Tianjin-Hebei and Yangtze River Delta Comprehensive Efficiency Value

\begin{tabular}{cccccc}
\hline year & 2014 & 2015 & 2016 & 2017 & 2018 \\
\hline Beijing & 0.838 & 0.967 & 0.999 & 1 & 0.97 \\
Tianjin & 1 & 1 & 1 & 0.777 & 0.744 \\
Hebei & 1 & 1 & 0.951 & 0.841 & 0.478 \\
Mean & 0.946 & 0.989 & 0.983 & 0.873 & 0.955 \\
\hline Shanghai & 1 & 1 & 0.917 & 0.995 & 0.958 \\
Zhejiang & 0.761 & 0.782 & 0.685 & 0.702 & 0.559 \\
Jiangsu & 1 & 1 & 1 & 1 & 1 \\
Anhui & 0.955 & 0.933 & 1 & 1 & 1 \\
\hline Mean & 0.929 & 0.929 & 0.901 & 0.924 & 0.879 \\
\hline
\end{tabular}

As shown in Table 1 , the overall efficiency value of Central Tianjin and Hebei in the Beijing-Tianjin-Hebei region in 2014 and 2015 were both 1. High-tech enterprises have made efficient use of various resource inputs in $\mathrm{R} \& \mathrm{D}$, and technology has given full play to its role. Although Beijing has not reached 1, it is always above 0.8 , and the level of resource input, management and utilization is relatively high. In the Yangtze River Delta region during the same period, Zhejiang has always been below 0.8 , lowering the overall level of the region. Its innovative resource input, business management methods and production scale need to be improved. At the same time, the standard deviation of the internal comprehensive efficiency of the Yangtze River Delta is about 0.100, which is higher than that of the Beijing-Tianjin-Hebei region, and the internal innovation resource allocation ability of the region is quite different.

In 2016, only Tianjin in the Beijing-Tianjin-Hebei region had a comprehensive efficiency value of 1 , with a regional average of 0.983 and a standard deviation of 0.028. At the same time, the comprehensive efficiency value of Jiangsu and Anhui in the Yangtze River Delta region reached 1 , and Zhejiang was as low as 0.685 , which is far from the regional average of 0.901 . There are still problems in the input of innovative resources. At the same time, the overall level of the region is slightly inferior to that of the Beijing-Tianjin-Hebei region.

In 2017, the comprehensive efficiency value of Tianjin and Hebei in the Beijing-Tianjin-Hebei region was lower than the regional average of 0.873 , and the standard deviation was 0.115. In the Yangtze River Delta region during the same period, Zhejiang was also 0.924 lower than the regional average, with a standard deviation of 0.148 .

In 2018, only Beijing in the Beijing-Tianjin-Hebei region had a comprehensive efficiency value above 0.9 , which is a relatively high level. Tianjin and Hebei are both at 0.8 , and Hebei is even as low as 0.478 , which is far from the other two places. In the Yangtze River Delta region, the rate is as low as 0.559 in Zhejiang, with poor resource allocation capabilities and low innovation resource transformation efficiency.
From a vertical perspective, the average level of comprehensive efficiency of high-tech enterprises in the Beijing-Tianjin-Hebei region from 2014 to 2016 was slightly better than that of the Yangtze River Delta region, but it was overtaken from 2017 to 2018, and the gap is gradually widening. At the same time, the overall efficiency standard deviation of the two places is on the rise as a whole, and the difference in overall efficiency within the region is expanding.

\subsection{Dynamic efficiency analysis based on Malmquist index}

This paper uses DEAP2.1 software to calculate the Malmquist value of the innovation efficiency of high-tech enterprises in the Beijing-Tianjin-Hebei and Yangtze River Delta regions.

Table2 2014 2018 Beijing-Tianjin-Hebei dynamic efficiency value decomposition item

\begin{tabular}{cccccc}
\hline year & effch & techch & pech & sech & tfpch \\
\hline 2014 & 1.021 & 1.114 & 0.988 & 1.033 & 1.138 \\
2015 & 0.976 & 1.089 & 0.978 & 0.999 & 1.063 \\
2016 & 0.962 & 1.052 & 1.025 & 0.939 & 1.013 \\
2017 & 0.879 & 1.531 & 0.952 & 0.923 & 1.346 \\
mean & 0.958 & 1.183 & 0.985 & 0.972 & 1.133 \\
\hline $\begin{array}{c}\text { accumulat } \\
\text { e }\end{array}$ & 0.843 & 1.954 & 0.943 & 0.894 & 1.649 \\
\hline
\end{tabular}

From Table2, it can be seen that the total factor productivity of high-tech enterprises in the Beijing-Tianjin-Hebei and Yangtze River Delta regions has maintained a steady increase year by year. The technological progress index has increased steadily every year, with a cumulative increase of $95.4 \%$ during the observation period, while the efficiency of technological innovation has been Decline year by year. Except for a slight improvement in pure technical efficiency from 2016 to 2017 , in other years the same scale efficiency has continued to decline by at least $1.5 \%$.

From Table 3, it can be seen that the total factor productivity of high-tech enterprises in all provinces and cities in the Beijing-Tianjin-Hebei region is greater than 1 , innovation efficiency is continuously improving, and there is also a lot of room for development. The situation in the Yangtze River Delta is similar to that of the Beijing-Tianjin-Hebei region, but the overall level is slightly better than that of the Beijing-Tianjin-Hebei region.

Decomposing total factor productivity into the product of changes in technological innovation efficiency and technological progress index, the technological progress index of the Beijing-Tianjin-Hebei and Yangtze River Delta regions are both greater than 1, and the frontier of technological production is moving in a favorable direction. It shows that the two regions as a whole have performed well in terms of technological improvement and re-creation ability in the technological production process. A technological progress index greater than 1 is an 
important factor for total factor productivity growth. In terms of technological innovation efficiency, the performance of the two regions is not satisfactory: in the Beijing-Tianjin-Hebei region, only Beijing has a technological innovation efficiency greater than one, and the Yangtze River Delta region also only has an Anhui technological innovation efficiency greater than one. The low level of technological innovation efficiency is a factor restricting the growth of total factor productivity.

In short, the overall innovation efficiency of high-tech enterprises in the Beijing-Tianjin-Hebei and Yangtze River Delta is in a state of continuous improvement, and it mainly relies on the steady increase of the technological progress index. In comparison, the scale efficiency of the Beijing-Tianjin-Hebei region and the pure technical efficiency of the Yangtze River Delta are the factors that restrict the development of innovation efficiency in the two regions.

Further, decomposing the efficiency of technological innovation into the product of pure technological efficiency and scale efficiency, the pure technological efficiency of the provinces and cities in the Beijing-Tianjin-Hebei region is about 1 , and the increase in production efficiency caused by pure technological changes such as technical training and organizational management is not obvious. In terms of scale efficiency, the average level is 0.934 . The current structure of high-tech enterprises is not suitable for innovation and development. The overall pure technical efficiency of the Yangtze River Delta region is 0.977 , and enterprises have insufficient technical levels and management methods; the average scale efficiency is 1.005 , and the current enterprise scale is conducive to innovation

Table3 Malmquist index and decomposition items of provinces and cities in the Beijing-Tianjin-Hebei and Yangtze River Delta from 2014 to 2018

\begin{tabular}{|c|c|c|c|c|c|}
\hline province & Shanghai & Zhejiang & Jiangsu & Anhui & mean \\
\hline effch & 0.989 & 0.926 & 1 & 1.011 & 0.982 \\
\hline techch & 1.111 & 1.103 & 1.104 & 1.4 & 1.18 \\
\hline pech & 0.992 & 0.914 & 1 & 1 & 0.977 \\
\hline sech & 0.997 & 1.013 & 1 & 1.011 & 1.005 \\
\hline tfpch & 1.099 & 1.021 & 1.104 & 1.416 & 1.16 \\
\hline province & BeiJing & Tianjin & Hebei & & mean \\
\hline effch & 1.037 & 0.929 & 0.832 & & 0.933 \\
\hline techch & 1.139 & 1.161 & 1.291 & & 1.197 \\
\hline pech & 0.996 & 1 & 1 & & 0.999 \\
\hline sech & 1.041 & 0.929 & 0.832 & & 0.934 \\
\hline tfpch & 1.181 & 1.078 & 1.073 & & 1.111 \\
\hline
\end{tabular}

\section{Conclusion}

Through the comparative analysis of the DEA and Malmquist index of high-tech enterprises in the Beijing-Tianjin-Hebei and Yangtze River Delta from 2014 to 2018, the conclusions are as follows:
From a static comparison: the high-tech industries in the Beijing-Tianjin-Hebei region from 2014 to 2016 The overall efficiency is better than the Yangtze River Delta region, but in 2017 to 2018, the Yangtze River Delta region surpassed. In comparison, pure technical efficiency and scale efficiency are the advantages of the Beijing-Tianjin-Hebei region and the Yangtze River Delta region respectively. From a dynamic analysis point of view: During the inspection period, the innovation efficiency of high-tech enterprises in the Beijing-Tianjin-Hebei region and the Yangtze River Delta is in a state of continuous improvement, which mainly depends on the improvement of the technological progress index.

Based on the above conclusions, this article puts forward the following suggestions:

In terms of technology and management; high-tech enterprises must have the awareness of continuous learning, and pay enough attention to knowledge updates, personnel training, and innovative methods; while increasing the intensity of talents and technology introduction, they must also pay attention to their own new production methods and resources. Exploration of investment ratio; learning advanced management concepts and humanized management systems; development must be steady and steady, and enterprise scale must not be blindly pursued; the government can take the lead in organizing technology, talent training and exchange meetings, and promoting the free flow of technical resources in the region.

\section{References}

1. Wang Jun. An Empirical Analysis of the Efficiency of China's Provincial Regional Innovation Economy. Exploration of Economic Issues, 10,105-114(2018)

2. Guo Shufen, Zhang Jun. Comparison of technological innovation efficiency and investment redundancy in 31 provinces and cities in China.Scientific research management ,39,04(2018)

3. Chen Weihua, Li Peng. Research on Enterprise Innovation Efficiency and Influencing Factors Based on Super-efficiency CCR-DEA Model.Journal of Beijing Vocational College of Economics and Management,33,02(2018)

4. Chi Renyong. Research on Enterprise Technological Innovation Efficiency and Its Influencing Factors.Quantitative Economics and Technical Economics Research,6,105-108(2003)

5. Xiao Wen, Lin Gaobang. Government Support, R\&D Management and Technological Innovation Efficiency-Based on Empirical Analysis of China's Industrial Industries.Management world 4,71-80(2014)

6. Yang Min, Chen Zeming. Comparable Measurement of Enterprise Innovation Efficiency in Heterogeneous Industries__DEA Secondary Superposition Based on Polarization Simulation.Soft science,29,07(2015) 